\title{
MuNEAN homenageia Wanda Horta
}

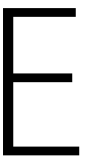

m entrevista à Enfermagem em Foco, Dra Maria Júlia Lemos, diretora do Museu Nacional de Enfermagem Anna Nery falta sobre a importância do museu para os profissionais de enfermagem e dá detalhes de uma exposição especial que acontece até o fim de abril.

Enfermagem em Foco: Conte-nos como a Exposição Gente que Cuida da Gente homenageia a enfermeira Wanda Horta? Maria Julia Lemos: A Exposição Gente que Cuida de Gente enfoca o ícone da enfermagem brasileira Wanda Horta, visionária, reconhecida por sua obra inovadora, comprometimento com a profissão, a contribuição na produção científica no processo de modernização da enfermagem no Brasil a partir da década de 1970. A Teoria
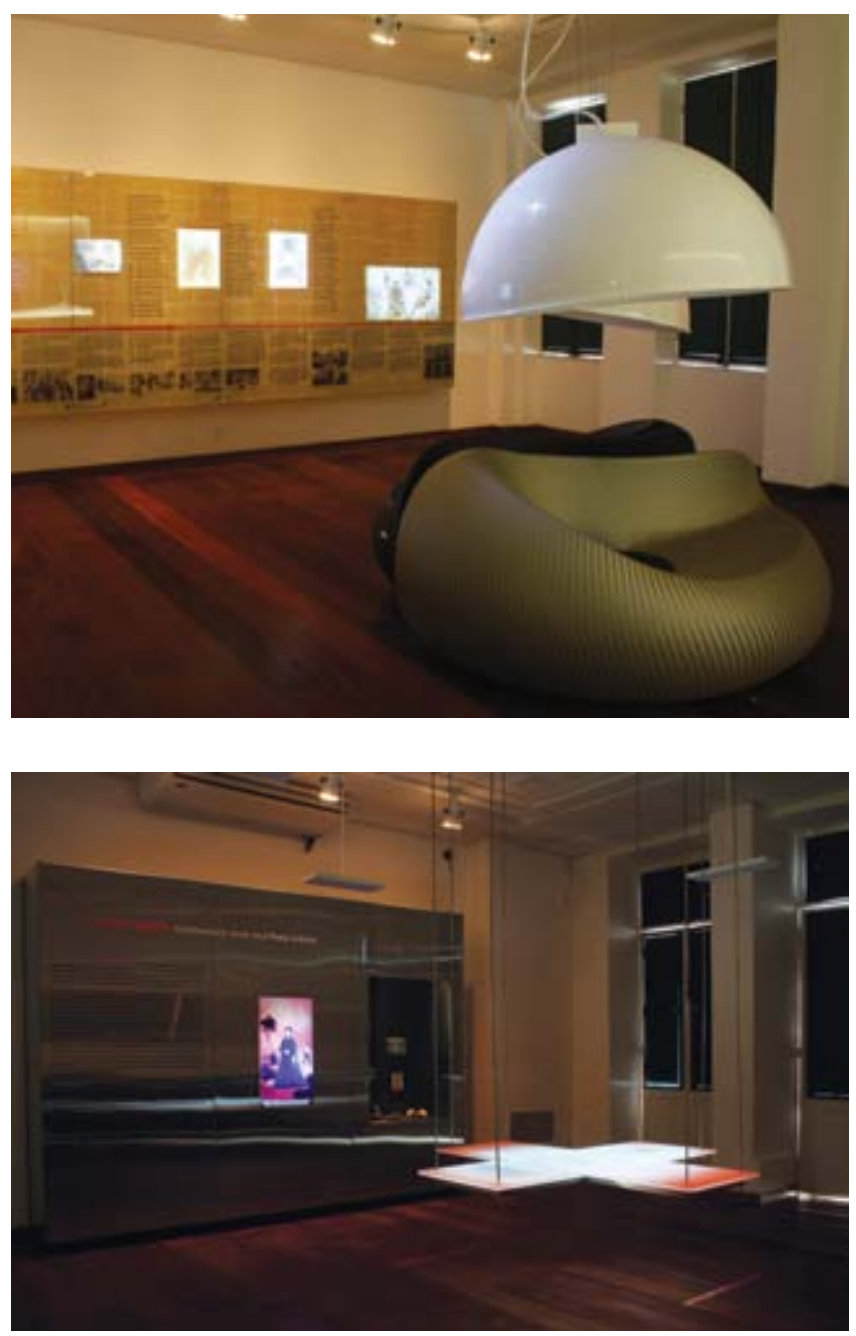

das Necessidades Humanas Básicas é o modelo teórico mais conhecido e utilizado em nosso país quando se aplica o Processo de Enfermagem e creditado à Wanda Horta.

\section{E.F.: Qual o principal destaque dessa} exposição?

M Julia: O destaque principal da exposição é que o visitante faça uma reflexão do ser Enfermeira(o), a importância da autonomia profissional. Outro destaque da exposição é sobre a CIPESC ${ }^{\circledR}$ Classificação Internacional de Práticas de Enfermagem em Saúde Coletiva, a importante ferramenta para a padronização da linguagem da Enfermagem em Saúde Coletiva. Outro destaque são os depoimentos de profissionais da importância da aplicação da Sistematização da Assistência de Enfermagem.

\section{E.F.: Quais são as exposições permanentes mais} importantes do MuNEAN?

M Julia: As exposições de longa duração apresentam recursos tecnológicos e painéis interativos sobre a história da enfermagem no Brasil e no mundo, destaque para o painel Anna Nery, considerada a patrona da Enfermagem Brasileira.

\section{E.F.: Qual a importância do MuNEAN para a história da saúde no Brasil?}

M Julia: A missão do Museu Nacional de Enfermagem Anna Nery é promover o reconhecimento, valorização e preservação da História da Enfermagem Brasileira, que tem como princípio valorizar e homenagear a atividade de enfermagem. Uma profissão que dá final feliz a tantas histórias merece ter a sua contada, não deixe de conferi-la.

www.munean.com

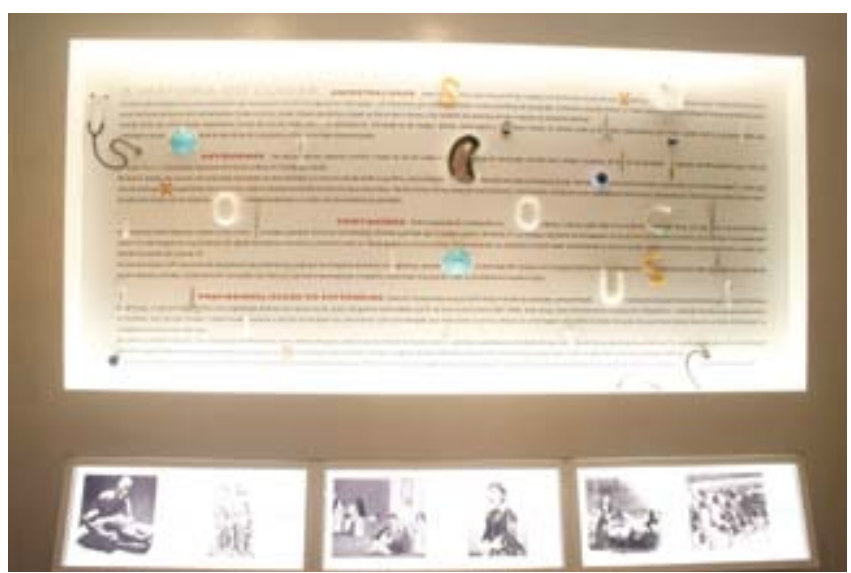

